\title{
Calcium and vitamin D nutrition and bone disease of the elderly
}

\author{
C Gennari*
}

Institute of Internal Medicine, University of Siena, Italy

\begin{abstract}
Osteoporosis, a systemic skeletal disease characterized by a low bone mass, is a major public health problem in EC member states because of the high incidence of fragility fractures, especially hip and vertebral fracture. In EC member states the high incidence of osteoporotic fractures leads to considerable mortality, morbidity, reduced mobility and decreased quality of life. In 1995 the number of hip fractures in 15 countries of EC has been 382.000 and the estimated total care cost of about 9 billion of ECUs. Given the magnitude of the problem public health measures are important for preventive intervention.

Skeletal bone mass is determined by a combination of endogenous (genetic, hormonal) and exogenous (nutritional, physical activity) factors. Nutrition plays an important role in bone health. The two nutrients essential for bone health are calcium and vitamin D. Reduced supplies of calcium are associated with a reduced bone mass and osteoporosis, whereas a chronic and severe vitamin D deficiency leads to osteomalacia, a metabolic bone disease characterized by a decreased mineralization of bone. Vitamin D insufficiency, the preclinical phase of vitamin D deficiency, is most commonly found in the elderly. The major causes of vitamin D deficiency and insufficiency are decreased renal hydroxylation of vitamin D, poor nutrition, scarce exposition to sunlight and a decline in the synthesis of vitamin D in the skin.

The daily average calcium intake in Europe has been evaluated in the SENECA study concerning the diet of elderly people from 19 towns of 10 European countries. In about one third of subjects the dietary calcium intake results were very low, between 300 and $600 \mathrm{mg} /$ day in women, and 350 and $700 \mathrm{mg} /$ day in men. Calcium supplements reduce the rate of bone loss in osteoporotic patients. Some recent studies have reported a significant positive effect of calcium treatment not only on bone mass but also on fracture incidence. The SENECA study, has also shown that vitamin D insufficiency is frequent in elderly populations in Europe. There are a number of studies on the effects of vitamin D supplementation on bone loss in the elderly, showing that supplementations with daily doses of 400-800 IU of vitamin D, given alone or in combination with calcium, are able to reverse vitamin D insufficiency, to prevent bone loss and to improve bone density in the elderly.

In recent years, there has been much uncertainty about the intake of calcium for various ages and physiological states. In 1998, the expert committee of the European Community in the Report on Osteoporosis-Action on prevention, has given the recommended daily dietary allowances (RDA) for calcium at all stage of life. For the elderly population, above age 65 the RDA is $700-800 \mathrm{mg} /$ day. The main source of calcium in the diet are dairy products (milk, yoghurts and cheese) fish (sardines with bones), few vegetables and fruits. The optimal way to achieve adequate calcium intake is through the diet. However, when dietary sources are scarce or not well tolerated, calcium supplementation may be used. Calcium is generally well tolerated and reports of significant side-effects are rare.

Adequate sunlight exposure may prevent and cure vitamin D insufficiency. However, the sunlight exposure or the ultraviolet irradiation are limited by concern about skin cancer and skin disease. The most rational approach to reducing vitamin D insufficiency is supplementation. In Europe, the RDA is 400-800 IU $(10-20 \mu \mathrm{g})$ daily for people aged 65 years or over. This dose is safe and free of side effects.
\end{abstract}


In conclusion, in Europe a low calcium intake and a suboptimal vitamin D status are very common in the elderly. Evidence supports routine supplementation for these people at risk of osteoporosis, by providing a daily intake of 700-800 $\mathrm{mg}$ of calcium and 400-800 IU of vitamin D. This is an effective, safe and cheap means of preventing osteoporotic fractures.

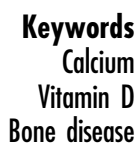

\section{Clinical and epidemiological aspects of osteoporosis}

\section{Osteoporosis and osteoporotic fractures}

Osteoporosis is a systemic skeletal diseases characterized by a low bone mass and microarchitectural deterioration of bone tissue, with a consequent increase in bone fragility and susceptibility to fracture ${ }^{1}$. Osteoporosis affects mainly postmenopausal women but also men, in either primary or secondary forms. Osteoporotic fractures, which represent the most relevant clinical aspects of the disease, occur in the hip, vertebrae, and distal radius. The main osteoporotic fractures differ in their mode of presentation. Whereas hip and radial fractures constantly come to the clinical attention, vertebral fractures have variable clinical presentation, in the sense that the majority of them are asymptomatic. Fractures of the hip incur the largest direct costs for health services, and occur in the elderly, particularly women, and give rise to substantial morbidity and mortality. Osteoporotic fractures of the vertebrae and forearm are of less economic significance, but also give rise to significant morbidity. Vertebral fractures, that are also more common in women than in men, are strongly related to age but appear earlier when compared to the hip fractures. The consequences of vertebral fractures include back pain and disability, kyphosis and height loss. Vertebral fractures cause a significant decrease in the quality of life, although the impact is less than that of hip fractures. Quality of life becomes progressively impaired as the number and severity of vertebral fractures increases. Future risk of osteoporotic fractures is greatly increased in patients with vertebral fractures.

Early detection of osteoporosis can be made at any age by measuring bone mineral density (BMD), in order to identify those individuals who need intervention for preventing fractures. According to the recommendations of a WHO task force, osteoporosis is defined in women as a BMD that lies 2.5 standard deviations or more below the average for the young healthy female population ${ }^{2,3}$. The same absolute BMD value can be utilized for men ${ }^{3}$. The preferred site for diagnostic assessment, particularly in the elderly, is the hip, using dual X-ray absorptiometry. Many studies indicate that the risk of fragility fractures increases progressively as BMD declines, and that there is a close relationship between the prevalence of osteoporosis, as assessed accordingly to the WHO criteria, and the incidence of fractures.

\section{Incidence/prevalence of osteoporotic fractures in Europe}

Osteoporosis is a major public health problem in EC member states because of the high incidence of fragility fractures, especially hip and vertebral fracture. Incident data on hip fractures have been obtained from Portugal, Spain, Italy, France, Greece and Turkey from the MEDOS study $^{4}$. For Finland, Sweden, and Netherlands data have been obtained from register studies ${ }^{5,6}$. Incidence data on hip fractures, both cervical and trochanteric, have been recently collected from several sources and published in a report on osteoporosis in the European Community ${ }^{7}$. The resulting age-specific incident data are shown in Table 1. It has been found that there is a marked variation in hip fracture incidence between countries, with higher rates in northern than in comparable populations in southern Europe. Data on prevalence of vertebral fracture in Europe have been collected from the EVOS study ${ }^{8}$, in which the fractures were estimated using two different methods of standardized radiological assessment. The age-standardized prevalence of vertebral deformity by sex and region is shown in Table 2.

\section{Socio-economic aspects of osteoporosis in Europe}

In EC member states the high incidence of osteoporotic fractures leads to considerable mortality, morbidity, reduced mobility and decreased quality of life. The demographic and socio-economic forecasts for the fifteen EU member states (Austria, Belgium, Denmark, Finland, France, Germany, Greece, Ireland, Italy, Luxembourg, Netherlands, Portugal Spain, Sweden and the UK) have been evaluated in the Report on osteoporosis in the European Community ${ }^{7}$. It has been estimated that the population of the 15 European countries consisting in 1995 of 373 million inhabitants, will decrease to 333 million in 2050. Men and women aged 65 years or more, on the other hand, will increase in number from 58 million in 1995 to 108 million in 2050. But the most dramatic change will be seen in the oldest group ( 80 years and above) in whom the incidence of osteoporotic fracture is greatest: from 13 million in 1995 to 43 million in 2050. In 1995 the number of hip fractures in 15 countries of EC has been 382.000 of which $80 \%$ occurred in women. In 1996 the total hospital cost of hip fractures has been of 3.6 billion ECUs, and the estimated total care cost about 9 billion ECUs. These numbers are likely to rise exponentially during the next few decades, as it has been estimated for the projected number of yearly incident hip 
Table 1 Age-specific incidence figures for hip fracture in the EU member states (/10000 population) ${ }^{7}$

\begin{tabular}{|c|c|c|c|c|c|c|c|c|}
\hline \multirow[b]{2}{*}{ Country } & \multicolumn{8}{|c|}{ Age-group } \\
\hline & $50-54$ & $55-59$ & $60-64$ & $65-69$ & $70-74$ & $75-79$ & $80-84$ & $85+$ \\
\hline \multicolumn{9}{|l|}{ Women } \\
\hline Austria & 3.360 & 7.11 & 14.10 & 26.50 & 47.7 & 82.4 & 138.0 & 351 \\
\hline Belgium & 2.720 & 5.86 & 11.80 & 22.60 & 41.1 & 72.0 & 122.0 & 317 \\
\hline Denmark & 4.100 & 8.62 & 17.00 & 31.90 & 57.2 & 98.4 & 164.0 & 416 \\
\hline Finland & 2.720 & 5.93 & 12.10 & 23.40 & 43.1 & 76.2 & 130.0 & 346 \\
\hline France & 0.598 & 1.66 & 4.21 & 9.94 & 22.1 & 46.5 & 93.4 & 262 \\
\hline Germany & 3.360 & 7.11 & 14.10 & 26.50 & 47.7 & 82.4 & 138.0 & 351 \\
\hline Greece & 2.530 & 5.40 & 10.80 & 20.40 & 36.9 & 64.2 & 108.0 & 232 \\
\hline Ireland & 1.820 & 4.27 & 9.32 & 19.10 & 37.3 & 69.5 & 125.0 & 362 \\
\hline Italy & 1.600 & 3.49 & 7.16 & 13.90 & 25.6 & 45.4 & 77.6 & 172 \\
\hline Luxembourg & 2.720 & 5.86 & 11.80 & 22.60 & 41.1 & 72.0 & 122.0 & 317 \\
\hline Netherlands & 2.720 & 5.86 & 11.80 & 22.60 & 41.1 & 72.0 & 122.0 & 317 \\
\hline Portugal & 2.630 & 5.18 & 9.64 & 17.10 & 29.0 & 47.7 & 75.8 & 151 \\
\hline Spain & 0.613 & 1.72 & 4.42 & 10.50 & 23.7 & 50.3 & 102.0 & 290 \\
\hline Sweden & 4.730 & 9.81 & 19.20 & 35.50 & 63.0 & 107.0 & 177.0 & 443 \\
\hline UK & 1.820 & 4.27 & 9.32 & 19.10 & 37.3 & 69.5 & 125.0 & 362 \\
\hline \multicolumn{9}{|l|}{ Men } \\
\hline Austria & 3.220 & 5.69 & 9.57 & 15.50 & 24.2 & 36.6 & 54.0 & 110.0 \\
\hline Belgium & 1.910 & 3.89 & 7.47 & 13.60 & 23.8 & 40.1 & 65.4 & 160.0 \\
\hline Denmark & 2.820 & 5.59 & 10.50 & 18.70 & 32.0 & 52.8 & 84.5 & 199.0 \\
\hline Finland & 2.950 & 5.71 & 10.40 & 18.20 & 30.5 & 49.4 & 77.5 & 177.0 \\
\hline France & 0.477 & 1.19 & 2.73 & 5.90 & 12.0 & 23.5 & 43.8 & 110.0 \\
\hline Germany & 3.220 & 5.69 & 9.57 & 15.50 & 24.2 & 36.6 & 54.0 & 110.0 \\
\hline Greece & 1.400 & 2.96 & 5.88 & 11.10 & 20.0 & 34.6 & 58.0 & 124.0 \\
\hline Ireland & 1.340 & 2.85 & 5.70 & 10.80 & 19.6 & 34.0 & 57.1 & 147.0 \\
\hline Italy & 1.120 & 2.22 & 4.15 & 7.40 & 12.7 & 20.9 & 33.4 & 67.0 \\
\hline Luxembourg & 1.910 & 3.89 & 7.47 & 13.60 & 23.8 & 40.1 & 65.4 & 160.0 \\
\hline Netherlands & 1.910 & 3.89 & 7.47 & 13.60 & 23.8 & 40.1 & 65.4 & 160.0 \\
\hline Portugal & 2.690 & 4.58 & 7.46 & 11.70 & 17.7 & 26.2 & 37.7 & 64.6 \\
\hline Spain & 0.545 & 1.35 & 3.12 & 6.73 & 13.8 & 26.8 & 50.0 & 126.0 \\
\hline Sweden & 4.510 & 8.76 & 16.10 & 28.20 & 47.4 & 77.1 & 122.0 & 280.0 \\
\hline UK & 1.340 & 2.85 & 5.70 & 10.80 & 19.6 & 34.0 & 57.1 & 147.0 \\
\hline
\end{tabular}

fractures that these fractures will double in 40 years (Table 3). Given the magnitude of the problem public health measures are important for preventive intervention.

\section{Nutritional factors related to osteoporosis}

\section{Calcium, vitamin $D$ and bone bealth}

Skeletal bone mass is determined by a combination of endogenous (genetic, hormonal) and exogenous (nutritional, physical activity) factors. In adolescence to attain the optimal peak bone mass the main determinants are genetic, nutritional and behavioural (exercise). In adult and elderly populations the main determinants of agerelated bone loss are represented by gonadal status, by the influence of some nutrients and by physical activity. Both a low peak bone mass and an high rate of bone loss represent risk factors for osteoporosis and osteoporotic fractures.

The mechanisms by which genetic factors influence bone mass have not yet been clarified. The heritability of peak bone mass is polygenic, and has been demonstrated in studies in twins suggesting that about $50 \%$ of the variance in peak bone mass may be determined genetically. There may also be genetic effects on bone

Table 2 Age standardized prevalence of vertebral deformity by sex and region in 17.342 subjects with a mean age of 64.1 years (mean center prevalence) ${ }^{8}$

\begin{tabular}{|c|c|c|c|c|c|c|}
\hline \multirow[b]{2}{*}{ Region } & \multicolumn{3}{|c|}{ Eastell method } & \multicolumn{3}{|c|}{ Mc Closkey method } \\
\hline & Male (\%) & Female (\%) & $F: M$ & Male (\%) & Female (\%) & $F: M$ \\
\hline Scandinavia* & 24.2 & 25.8 & 1.07 & 16.2 & 20.0 & 1.23 \\
\hline Western Europe† & 20.6 & 19.2 & 0.93 & 11.6 & 11.4 & 0.98 \\
\hline East Europe & 18.0 & 18.4 & 1.02 & 11.3 & 11.1 & 0.98 \\
\hline Mediterranean§ & 21.6 & 22.6 & 1.05 & 13.6 & 12.2 & 0.90 \\
\hline
\end{tabular}

* Norway, Sweden

† Austria, Belgium, France, Germany, Holland, U.K.

‡ Croatia, Czech Rep., Slovakia, Germany, Hungary, Poland, Russia.

$\S$ Greece, Italy, Portugal, Spain, Turkey. 
Table 3 Projected numbers of yearly incident hip fractures in the EC member states $(\times 1000)^{7}$

\begin{tabular}{lccccccc}
\hline Year & 1995 & 2000 & 2010 & 2020 & 2030 & 2040 & 2050 \\
\hline Women & 302 & 326 & 385 & 456 & 547 & 654 & 742 \\
Men & 80 & 88 & 110 & 139 & 172 & 207 & 230 \\
Total & 382 & 414 & 495 & 595 & 719 & 861 & 972 \\
F/M ratio & 3.7 & 3.7 & 3.5 & 3.2 & 3.1 & 3.1 & 3.2 \\
\hline
\end{tabular}

remodeling. A number of potential candidate genes have been explored in linkage and association studies. Although earlier reports indicated that vitamin D receptor gene polymorphisms were strongly related to bone mass subsequent studies have not always confirmed these findings 9 . Other candidate gene which are being investigated include the oestrogen receptor gene and genes for various cytokines and growth factors.

Nutrition plays an important role in bone health. The two nutrients essential for bone health are calcium and vitamin D. Reduced supplies of calcium may be associated with a reduced bone mass and osteoporosis, whereas a chronic and severe vitamin D deficiency leads to osteomalacia, a metabolic bone disease characterized by a decreased mineralization of bone matrix and an increased osteoid volume. Vitamin D deficiency can be confirmed by measuring the serum concentration of 25-hydroxyvitamin D (25(OH)D), which is the major circulating metabolite and represents the storage form of vitamin D. In patients with osteomalacia, serum $25(\mathrm{OH}) \mathrm{D}$ levels are usually below $5-6 \mathrm{ng} / \mathrm{ml}$ and often undetectable ${ }^{10-12}$. Biochemically osteomalacia is characterized by normal or low serum concentrations of calcium and phosphate, and increased activity of alkaline phosphatase. Vitamin D deficiency is common in the elderly, particularly in instituzionalized subjects. The major causes of vitamin D deficiency are scarce exposition to sunlight, a decline in the synthesis of vitamin $\mathrm{D}$ in the skin, poor nutrition, and decreased renal hydroxylation of vitamin $\mathrm{D}^{12}$. A subclinical vitamin $\mathrm{D}$ deficiency, as characterized by a circulating level of 25(OH)D comprised between 6 and $30 \mathrm{ng} / \mathrm{ml}$ is also common in the elderly. This condition, that has been defined vitamin $\mathrm{D}$ insufficiency $^{10-12}$, is increasingly being recognized as a distinct pathological skeletal entity, characterized by normocalcemia and normal bone mineralization and by an increase in circulating levels of parathyroid hormone (PTH). In the presence of osteoporosis, vitamin D insufficiency may amplify bone loss and thus enhance fracture risk. It follows that at any age, but particularly in the elderly, an adequate intake of both calcium and vitamin $\mathrm{D}$, is important for the preservation of bone mass and prevention of osteoporosis.

\section{Dietary calcium intake and bone mass}

In recent years convincing evidence has been given that dietary calcium intake is positively related to bone mineral density in children and adolescents ${ }^{13}$. In adolescents, the higher the calcium intake, the greater the peak bone mass ${ }^{14}$. A positive correlation between bone mass and calcium intake has been demonstrated also in adults, particularly in premenopausal women ${ }^{15}$.

In adults a low bone mass increases the risk of fragility fracture. It has been estimated that a 1 SD decrease in hip bone mineral density is associated with 2.5 -fold increased risk of hip fracture ${ }^{16}$. The relationship between calcium intake and fracture rate is less certain. Some studies have reported an inverse correlation between dietary calcium intake and fracture (mainly of the hip), others have not demonstrated any significant correlation and some have even shown a positive correlation between calcium intake and hip fracture ${ }^{17}$.

The daily average calcium intake in Europe has been evaluated in the SENECA study (Table 4), concerning the diet and health of elderly people from 19 towns of 10 European countries ${ }^{18}$. The study was performed on random samples of the residents stratified for age and sex, age-range 71-76 years. Dietary intake data were collected by a validated dietary history method. In about one third of subjects the dietary calcium intake results were very low: between 300 and $600 \mathrm{mg} /$ day in women, and between 350 and $700 \mathrm{mg} /$ day in $\mathrm{men}^{18}$.

\section{Effects of calcium on bone mass}

There is good evidence that calcium intake influences bone mass in all age groups. In children and adolescents a positive effect of calcium on bone mass has been reported in cross-sectional and intervention studies ${ }^{19-21}$. In a prospective study the dietary calcium intake in childhood and adolescence resulted positively related to bone mass in young women ${ }^{13}$. A recent meta-analysis of 33 studies has shown that there was a significant association between calcium intake and bone mass in premenopausal women, while this relationship was not significant in young men ${ }^{15}$.

In adults, calcium supplementation reduces the rate of age-related bone $\operatorname{loss}^{22}$. A review of 20 prospective calcium trials in postmenopausal women concluded that

Table 4 Dietary calcium intake of elderly ( $75-80$ years) in some European countries ${ }^{18}$ (The data are presented in percentiles P10 and P90)

\begin{tabular}{lcc}
\hline & \multicolumn{2}{c}{ Calcium intake (mg/day) } \\
\cline { 2 - 3 } & \multicolumn{1}{c}{ Men } & Women \\
\hline Belgium & $280-1100$ & $320-1160$ \\
Denmark & $540-1500$ & $320-1160$ \\
France & $430-960$ & $470-1090$ \\
Ireland & $460-1350$ & $630-1310$ \\
Italy & $470-1200$ & $430-1090$ \\
Netherlands & $610-1600$ & $720-1440$ \\
Portugal & $260-1170$ & $350-1030$ \\
Poland & $300-1350$ & $450-1230$ \\
Spain & $410-1570$ & $550-1670$ \\
Switzerland & $450-1240$ & $570-1480$ \\
\hline
\end{tabular}


calcium supplementation reduced bone loss on average by about $1 \%$ year $^{23}$. In the elderly, calcium supplementation also reduces bone loss and the lower the dietary calcium intake the better the response in bone ${ }^{24}$.

The most part of randomized controlled calcium intervention trials examining change in bone mineral density have been performed in postmenopausal women $^{22}$. Women with low to moderate calcium intakes benefit significantly from calcium supplementation ${ }^{25}$. Some studies suggest that recently estrogen-deficient women (within the first 5 years of menopause) are generally less responsive to calcium than women 6 or more years since menopause ${ }^{25,26}$. Recently, a metaanalysis of studies concerning the bone mineral density responses to hormone replacement therapy in relation to calcium intake, has shown that the bone mineral density gain at each skeletal site assessed (spine, hip and forearm) was significantly greater in women who increased their calcium intake than in women who took hormonal replacement therapy alone ${ }^{27}$.

The mechanism by which calcium supplementation slows bone loss is probably through a reduction in serum parathyroid hormone (PTH). With age there is an increase in serum PTH and bone turnover ${ }^{28}$ due to the combined effects of reduced calcium intake and absorption ${ }^{29}$ and to vitamin $\mathrm{D}$ insufficiency ${ }^{30}$. Low doses of calcium of $250 \mathrm{mg}$ result in acute suppression of serum PTH and low habitual calcium intakes are associated with higher serum PTH levels than higher calcium intakes ${ }^{31}$. The beneficial effects on bone of calcium supplements may therefore be mediated via an antiresorptive effect. In general the most consistent effects of calcium are observed in the appendicular skeleton, while the positive effect on trabecular bone appear to be transient ${ }^{32}$. In a recent study, where citrate and calcium infusions were used to characterize the impact of age and gender on PTH secretion in normal subjects, ageing was associated with an increase in PTH secretory response to changes in serum calcium, in both women and $\operatorname{men}^{33}$.

Although calcium alone is insufficient to treat established osteoporosis, treatment with any of the bone-active hormonal or pharmacologic agents will be less effective if attention is not given to ensuring an adequate intake of calcium. Published clinical trials investigating the efficacy of antiresorptive agents, including estrogen, calcitonin and bisphosphonates, on bone mass have involved calcium supplementation in both the treatment and control groups. Therefore, the additional benefit, if any, of calcium supplement with antiresorptive treatment on bone mass is not known. There is some evidence that a calcium supplementation may have a synergistic effect with antiresorptive agents. In a recent meta-analysis of patients treated with either estrogen or calcitonin it has been found that the treatment-induced improvement in bone density was two- to fourfold greater if calcium was combined with the active agent ${ }^{27}$. However, no studies have addressed the question of how much calcium may be required during treatment with bone-active agents. The optimal calcium intake in conjunction with antiresorptive therapy is unknown, although there is a general agreement to provide at least $1200 \mathrm{mg}$ /day of calcium in patients receiving antiresorptive agents.

Both mechanical loading on the skeleton and adequate nutrition are essential for the maintenance of bone mass. Exercise and calcium intake are important determinants of peak bone mass during childhood and adolescence ${ }^{13,34}$. Later in life, some of the age-related bone loss results from a decline in physical activity ${ }^{35}$. Studies evaluating the combined effect of increased calcium intake and increased exercise in young and postmenopausal women have shown more striking benefits than those produced by either modality alone $\mathrm{e}^{19,36}$.

\section{Effects of calcium on osteoporotic fractures}

Calcium supplements decrease bone turnover by suppressing PTH secretion and reduce the rate of bone loss in osteoporotic patients. Recently, some studies have reported a significant positive effect of calcium treatment not only on bone mass but also on fracture incidence. In the epidemiological case-control study performed in six European countries (MEDOS) calcium treatment has been reported to reduce the risk of hip fractures ${ }^{37}$. Three recent controlled trials have suggested that calcium supplementation may reduce fracture incidence in postmenopausal women. In one study women with a mean age of 73.6 years and a low dietary calcium intake (mean $430 \mathrm{mg} / \mathrm{d}$ ) were randomly treated with calcium (600 mg twice daily) or placebo ${ }^{38}$. After 4 years women with prevalent fractures at the beginning of the study developed less fractures in the calcium group than in the placebo group. This study indicates that relatively high doses of calcium supplements given to calcium-deficient elderly women with vertebral fractures may reduce the incidence of new fractures. In another study performed in osteoporotic women with low bone mass but without vertebral fractures a significant reduction in the first vertebral fracture was observed as a result of calcium supplementation $^{39}$. In a smaller trial, women taking $1000 \mathrm{mg}$ of supplemental calcium per day presented less vertebral fractures than women taking placebo ${ }^{40}$. These trials with fracture data although performed in a limited number of patients found reductions in fracture incidence ranging from $25 \%$ to $50 \%$ in patients with an initial low calcium intake (ranging from 400 to $700 \mathrm{mg}$ /day). It remains to be determined whether calcium supplementation will reduce fractures in subjects with normal starting intakes of calcium (above $1000 \mathrm{mg} /$ day). However, these studies should be interpretated with caution because they were not powered to assess the effects of calcium supplementation on fractures ${ }^{17}$. 


\section{Vitamin D status and bone bealth}

The major source of vitamin D is the skin, where it is produced by the action of ultraviolet light on steroid precursors. Vitamin D is also present in a limited number of foods, and the dietary sources of the vitamin can be important under circumstances of decreased sunlight exposure. Vitamin D is not a true vitamin, but a prosteroid hormone that is biologically inert until metabolized. In the liver, vitamin D is metabolized to $25(\mathrm{OH}) \mathrm{D}$, which functions as the major storage form by virtue of its long half-life. In the kidney $25(\mathrm{OH}) \mathrm{D}$ is further metabolized by a $1 \alpha$-hydroxylase enzyme to 1,25 -dihydroxyvitamin $\mathrm{D}(1.25(\mathrm{OH}) 2 \mathrm{D})$, the hormone responsible for the biological effects of vitamin D. Vitamin D is important for bone, for its role in promoting intestinal calcium absorption and mineralization of bone matrix.

Vitamin D status may be evaluated by measuring the serum concentration of $25(\mathrm{OH}) \mathrm{D}$. Since $25(\mathrm{OH}) \mathrm{D}$ concentrations are mainly affected by sunlight exposure and intensity $^{41}$, the two major determinants of serum $25(\mathrm{OH}) \mathrm{D}$ levels are the season and the geographical location. In fact, the cutaneous synthesis of previtamin D is maximal in summer and minimal in winter, and an inverse association exists between mean 25(OH)D concentration and latitudes ${ }^{42}$. In healthy adult subjects the lower limit of the normal range for serum $25(\mathrm{OH}) \mathrm{D}$ is approximately $30 \mathrm{ng} / \mathrm{ml}^{10}$. When serum 25(OH)D values fall below this threshold, there is an increase in parathyroid hormone (PTH) secretion ${ }^{10}$, that may increase bone resorption and contribute to the osteoporosis process. A long-lasting and severe deficiency of vitamin $\mathrm{D}$, as defined by a serum level of $25(\mathrm{OH}) \mathrm{D}$ lower than $6 \mathrm{ng} / \mathrm{ml}$, is associated with defective mineralization resulting in rickets in children and osteomalacia in adults. Vitamin D insufficiency, the preclinical phase of vitamin D deficiency, as defined by a serum level of $25(\mathrm{OH}) \mathrm{D}$ comprised between 6 and $30 \mathrm{ng} / \mathrm{ml}$, causes a reduced calcium supply and a secondary hyperparathyroidism. If this state remains chronic, osteopenia results.

The state of vitamin D insufficiency is most commonly found in the elderly. With age there is a decrease in serum $25(\mathrm{OH}) \mathrm{D}$ due to decreased sunlight exposure and possibly to decreased skin synthesis. The reduction in renal function with age giving rise to reduced renal $1,25(\mathrm{OH}) 2 \mathrm{D}$ production may be a contributing factor. Intestinal calcium absorption also decrease with age, partly because of decreased renal hydroxylation of $25(\mathrm{OH}) \mathrm{D}$, and partly because of decreased responsiveness of the intestinal mucosa to circulating 1,25(OH)2D. This intestinal resistance to $1,25(\mathrm{OH}) 2 \mathrm{D}$ has been observed in postmenopausal women showing an intestinal malabsorption of calcium ${ }^{43,44}$.

During the last decade evidence has accumulated documenting vitamin D deficiency or insufficiency in elderly populations in Europe. A Dutch investigation found vitamin D insufficiency in 16\% of the healthy elderly population and in $60 \%$ of people experiencing a hip fracture ${ }^{45}$. In German patients with hip fracture, vitamin D insufficiency occurred in 69\% of the women and in $55 \%$ of the men ${ }^{46}$.

In 1992 a review was published dealing with 117 reports on vitamin D status of young adults and elderly, from 1971 to 1990, in different geographic regions (North America, Scandinavia, Central/Western Europe) ${ }^{47}$. European values were significantly lower compared with Scandinavia and North America during winter, spring and autumn, particularly in healthy elderly. In elderly populations the prevalence of vitamin D insufficiency during the winter was lower in North America and Scandinavia (25\%), than in Western/Central Europe $(60 \%)^{47}$.

A more recent population-based study, the SENECA study, concerning an investigation of the diet of elderly people (71-76 years) from 19 towns in 11 European countries, has shown that vitamin D insufficiency was much more frequent in Mediterranean countries than in Northern Europe ${ }^{48}$. This difference may be unexpected, because sunlight exposure is much lower in Northern Europe than in Southern Europe. The reason for this could be a different attitude towards sunlight exposure and the dietary enrichment with vitamin D that is compulsory in Northern countries, such as Norway, Denmark, the Netherlands and Belgium. In the SENECA study $36 \%$ of men and $47 \%$ of women in wintertime had 25(OH)D concentrations below $12 \mathrm{ng} / \mathrm{ml}$ $(\text { Table } 5)^{48}$.

More recently, two French population-based studies conducted in normal adults (SUVIMAX) and in healthy elderly (EPIDOS) have shown that a large percentage of the French urban population has vitamin D insufficiency during wintertime ${ }^{10,49}$.

Table 5 Prevalence of low concentrations of 25-hydroxyvitamin D in elderly (824 subjects, age range $70-75$ years) of different European countries ${ }^{48}$

\begin{tabular}{|c|c|c|c|c|c|}
\hline \multirow[b]{2}{*}{ Country } & \multirow[b]{2}{*}{$\begin{array}{l}\text { Latitude } \\
\text { ('north) }\end{array}$} & \multicolumn{2}{|r|}{ Men } & \multicolumn{2}{|c|}{ Women } \\
\hline & & $n$ & $\begin{array}{c}\leq 12 \mathrm{ng} / \mathrm{ml} \\
(\%)\end{array}$ & $n$ & $\begin{array}{c}\leq 12 \mathrm{ng} / \mathrm{ml} \\
(\%)\end{array}$ \\
\hline Norway & 61 & 32 & 28 & 28 & 18 \\
\hline Denmark & 56 & 33 & 24 & 25 & 32 \\
\hline Netherlands & 52 & 30 & 20 & 29 & 38 \\
\hline Belgium & 51 & 31 & 26 & 29 & 24 \\
\hline France & 49 & 30 & 47 & 26 & 62 \\
\hline France & 48 & 16 & 38 & 11 & 36 \\
\hline Hungary & 47 & 19 & 37 & 23 & 52 \\
\hline Switzerland & 47 & 24 & 25 & 24 & 25 \\
\hline Switzerland & 47 & 26 & 12 & 32 & 12 \\
\hline Switzerland & 46 & 22 & 45 & 25 & 44 \\
\hline France & 45 & 35 & 34 & 25 & 44 \\
\hline Spain & 43 & 27 & 52 & 29 & 86 \\
\hline Italy & 42 & 12 & 42 & 13 & 92 \\
\hline Portugal & 39 & 29 & 31 & 30 & 33 \\
\hline Greece & 38 & 21 & 52 & 25 & 80 \\
\hline Greece & 35 & 27 & 70 & 36 & 83 \\
\hline
\end{tabular}




\section{Effects of vitamin $D$ on bone mass and on osteoporotic fractures}

In the last decade, a positive association between serum $25(\mathrm{OH}) \mathrm{D}$ concentrations and bone mass has been reported in adult and elderly populations from North America and Europe. Several studies have shown a relationship between bone mineral density, vitamin D insufficiency and secondary hyperparathyroidism in the elderly ${ }^{50-54}$ but also in postmenopausal and middle-aged women $^{50,55,56}$. In a cross-sectional study conducted in the UK a positive relation between serum 25(OH)D values and BMD was observed in a group of middle-aged women $^{56}$. In an American study performed in postmenopausal women with low vertebral bone mass, a relation between vertebral BMD and PTH values was found only in subjects with low $25 \mathrm{OH}$ vitamin D values ${ }^{55}$. In another study a significant association between low femoral BMD and low $25(\mathrm{OH}) \mathrm{D}$ levels was described in normal women older than 60 years $^{51}$.

The observation in several studies of a seasonal variation in BMD may provide indirect evidence that relatively small changes in vitamin $\mathrm{D}$ status may have significant effects on bone mass. A prospective study has shown that supplementation with small doses of vitamin $\mathrm{D}$ is able to prevent the fall in BMD that occurs during the winter in postmenopausal women ${ }^{57}$.

There are a number of studies on the effects of vitamin D supplementation on bone loss in the elderly. Some studies have been performed with vitamin D alone ${ }^{58-60}$, some others with vitamin D and calcium supplementa$\operatorname{tion}^{24,61-63}$. It appears from these studies that supplementations with daily doses of 400-800 IU of vitamin D, given alone or in combination with calcium, are able to reverse vitamin D insufficiency, to reduce secondary hyperparathyroidism, to prevent bone loss and to improve bone density in elderly.

Two randomised controlled prospective studies ${ }^{24,64}$ and a retrospective study ${ }^{37}$ have examined the effects of calcium and vitamin D supplementation on osteoporotic fracture incidence. In the epidemiological case-control study conducted in six European Mediterranean countries (MEDOS study) treatment with vitamin $\mathrm{D}$ has been reported to be associated with a reduced incidence of hip fracture ${ }^{37}$. The first prospective study was performed on a French cohort of over 3000 institutionalised elderly women (mean age 84 years) during treatment with either vitamin D (800 IU/day) and calcium (1.2 gr/day) or placebo for three years ${ }^{64}$. Active treatment significantly reduced the incidence of new hip fractures by $29 \%$ and that of all non vertebral fractures by $24 \%{ }^{64}$. Of particular interest are the results of the second placebo-controlled trial of the effect of calcium $(500 \mathrm{mg} /$ day $)$ and vitamin D (700 IU/day) in healthy community-based men and women older that 65 years, with a mean dietary calcium intake of about $700 \mathrm{mg} / \mathrm{day}^{24}$. After three years $12.9 \%$ of subjects treated with placebo and $5.9 \%$ of those treated with vitamin D and calcium sustained non-vertebral fractures, a statistically significant difference ${ }^{22}$.

However, the relative contribution of vitamin D and calcium to these benefits is still unknown. In a Dutch study, the administration of 400 IU daily of vitamin D to elderly subject with a high calcium intake produced no reduction in fracture rate ${ }^{65}$. On the other side, an open randomised study of a single annual injection of 150.000-300.000 IU of vitamin D each autumn in an elderly Finnish population showed a significant reduction in overall fracture rate but not in the rate of hip fractures $^{66}$. Thus, the problem whether vitamin D supplementation alone is able to prevent hip fracture remains unresolved. Nevertheless, all these studies underline the need for an adequate vitamin $\mathrm{D}$ and calcium nutrition in the elderly, particularly in populations at risk of osteoporotic fractures like individuals living indoors in nursing homes, who have a high prevalence of vitamin D deficiency or insufficiency.

The $1 \alpha$-hydroxylated forms of vitamin D, 1,25-dihydroxycholecalciferol or calcitriol, and $1 \alpha$-hydroxycholecalciferol or alfacalcidol, have been proposed as possible therapies for osteoporosis. Both compounds strongly stimulate the intestinal calcium absorption, and the response is dose-dependent. This leads to a suppression of PTH secretion and a decrease in bone turnover. Over the past two decades, several clinical trials have been performed in osteoporotic patients using calcitriol or alfacalcidol, at doses from 0.25 to $2.0 \mu \mathrm{g} /$ day. A positive effect of both compounds on BMD was seen in some clinical trials, whereas in others there was no change in $\mathrm{BMD}^{67}$. In addition, there is not yet a definite answer as to whether these compounds decrease the incidence of osteoporotic fractures $^{67}$. The therapeutic effects seem to be pharmacological rather than physiological, and some concern exists about the potential side-effects of this treatment. Hypercalcemia and impairment of renal function are rare with lower doses (up to $0.5 \mu \mathrm{g} /$ day) but more frequent with higher doses (1-2 $\mu \mathrm{g}$ /day). For these reasons, treatment with calcitriol or alfacalcidol necessitates monitoring of serum calcium and renal function, unlike treatment with vitamin D.

\section{Otber mutrients and bone bealth}

Many nutrients may also influence bone health, including macronutrients, such as protein, fat and carbohydrates, and micronutrients, such as vitamin $\mathrm{K}$ and $\mathrm{C}$, phosphorus, magnesium, zinc, copper and fluoride.

As it concerns macronutrients, protein, fat and carbohydrates are the energy nutrients, but they may also have nonenergy roles in skeletal growth and maintenance. An adequate intake of protein is essential for the synthesis of bone matrix. Protein intake and bone mass gains are positively correlated in children and an inadequate protein nutrition during puberty results in suboptimal peak bone mass ${ }^{68}$. In the elderly, the most common 
nutritional deficiency is a protein-energy malnutrition. In the aged-population protein malnutrition increases the propensity to fall and could also accelerate age-dependent bone $\operatorname{loss}^{69}$. Recently, the relationship between dietary protein intake, physical performance and BMD was examined in hospitalized elderly subjects ${ }^{70}$. The group with high protein intake (more than $1 \mathrm{~g}$ per $\mathrm{kg}$ of ideal body weight) had a greater BMD and muscle strength than the group with low protein intake ${ }^{70}$. Nevertheless, an excessive protein supply could negatively affect the balance of calcium and consequently bone mass ${ }^{71}$. It has been observed that a high protein intake may be associated with increased urinary calcium excretion, and thus with a decreased bone mineral density. The recommended dietary allowance for protein in young adults is $0.8 \mathrm{~g} / \mathrm{kg}$ of body weight, but in healthy elderly subjects the requirement for protein is modestly increased $(1 \mathrm{~g} / \mathrm{kg} \text { b.w. })^{69}$. The favorable effects of other macronutrients, such as fat and carbohydrates, remain to be established.

Bone matrix contains collagenous and non collagenous proteins whose synthesis requires several micronutrients, including vitamins $\mathrm{C}$ and $\mathrm{K}$, and minerals, such as copper and zinc. The relationship of the status of some of these micronutrients to bone health are not well studied because they have not been available in food composition databases. Vitamin $\mathrm{C}$ is necessary for hydroxylation of protein and copper is a cofactor for lysyl-oxidase, an enzyme required in forming collagen cross-links. Bone loss has been ascribed to deficiencies of copper ${ }^{72}$ and of zinc $^{73}$. However, the causal relationship between these deficiencies and bone mineral loss and the role of these micronutrients in the osteoporotic process occurring in the elderly are uncertain.

Recently, vitamin $\mathrm{K}$ has been suggested to play a specific role in osteoporosis, and particularly in the risk of hip fracture. In clinical studies, a lower level of vitamin K1 and K2 was found in patients sustaining hip fracture ${ }^{74}$. Vitamin $\mathrm{K}$ is essential for the production of gammacarboxylated glutamyl residues present in osteocalcin (OC), which is stored in the skeleton and influences bone metabolism. A positive relationship has been found between the serum level of undercarboxylated osteocalcin (UcOC) and ageing ${ }^{75}$. Vitamin $\mathrm{K}$ deficiency is associated with the elevation of serum UcOC levels in the elderly ${ }^{76}$. These elevated serum UcOC concentrations are associated with both femoral low bone mass and an increased risk in hip fracture in elderly women ${ }^{76,77}$.

Almost $85 \%$ of the body's phosphorus is present in crystalline form in bone as hydroxyapatite (Ca5OH(PO4)3). About 15\% is present in the extracellular fluids largely in the form of inorganic phosphate ions and in soft tissues in the form of phosphate esters. In contrast to calcium, the serum phosphate concentration varies quite widely and is influenced by diet. An adequate serum phosphate level is important in maintaining a sufficient ion product for normal mineralization of bone matrix. Intestinal absorption of phosphate is dependent on both passive and active phosphate transport. The latter is stimulated by vitamin $\mathrm{D}$, and the intestinal phosphate absorption is reduced in vitamin D-deficiency. However, the availability of phosphate in the diet appears to be the major determinant of the phosphate input from intestine to the body. Because phosphate is a major component of all cells and the main dietary sources of phosphate are animal products, a phosphate depletion by diet is unusual. Among healthy adults the normal range of dietary phosphate intake is $25-60 \mathrm{~mm} /$ day $(775-1860 \mathrm{mg}$ of phosphorus/day $)^{78}$. A low dietary intake of phosphate, lower than $10 \mathrm{mmol} /$ day (310 $\mathrm{mg}$ of phosphorus/day) may be associated with a negative phosphate balance ${ }^{78}$. Phosphate deficiency has been reported to cause rickets and osteomalacia. The subjects at risk for hypophosphatemic osteomalacia include patients receiving total parenteral nutrition, and those taking antacids for long periods. Antacid-induced osteomalacia results from aluminum complexation with dietary phosphate in the intestinal lumen, which prevents phosphate absorption. Low phosphate intakes are also relatively common among elderly. On the other side, a high dietary intake of phosphate, when combined with a low dietary intake of calcium, may increase serum PTH levels and consequently may have adverse effects on bone mass. In fact, it has been shown that an acute increase in dietary phosphate intake may produce an increased secretion of $\mathrm{PTH}^{79}$.

Approximately 50-60\% of the magnesium in the body is in bone. Magnesium is required for matrix and mineral metabolism as an essential cofactor in the function of many enzymes, including those concerned with the transfer of phosphate groups and the metabolism of ATP. Magnesium concentration in the extracellular fluids results from the kidney. The kidney is mainly responsible for this regulation. Urinary excretion of magnesium is directly related to dietary magnesium intake. The mechanisms mediating magnesium absorption in the small intestine are poorly defined. The net quantity of magnesium absorbed appears to be primarily a function of magnesium intake. Because magnesium is a constituent of all cells and normal diets contain foods of cellular origin, dietary magnesium deficiency is unusual. A reduced intestinal magnesium absorption occurs with intestinal diseases causing malabsorption or as a consequence of laxative abuse. A decreased serum magnesium level has been reported in postmenopausal osteoporotic women ${ }^{80}$, but the relation between magnesium deficiency and bone mineral loss remains to be defined.

Fluoride is considered one of the few agents stimulating bone formation. The demonstration of a lower prevalence of osteoporosis in areas with moderately elevated fluoride levels in the drinking 
water motivated the use of fluoride in treatment of involutional osteoporosis. However, prospective studies have shown that pharmacological doses of fluoride increase bone mass but may have negative effects on bone strength and fracture risk. The fluoride content of food is low, and the daily dietary intake of fluoride is only about 0.3 to $0.5 \mathrm{mg}$. Fluoridated drinking water may provide an additional intake of $1 \mathrm{mg} / \mathrm{day}$. An intake of 1 or $2 \mathrm{mg} /$ day decreases the incidence of dental caries in children. In addition to the beneficial effects on teeth, fluoridation of water might have a protective effect on the skeleton ${ }^{81}$. In Finland, a population based study has shown increased axial bone density in postmenopausal women exposed to $1 \mathrm{mg} / \mathrm{L}$ of fluoride for more than 10 years $^{82}$. However, concerns remain about possible adverse effects of water fluoridation on risk of fractures, particularly of the hip. At this regard, some studies have suggested a positive association between the concentration of fluoride in water and incidence of fractures, but other have found no association or even an inverse relation. A recent population-based case-control study in the UK found no evidence of increased hip fracture risk among individuals with lifetime exposure to water containing fluoride concentrations greater than $0,9 \mathrm{mg} /$ $\mathrm{L}^{83}$. These data, combined with those of another North American study conducted in a cohort of 2076 women exposed to fluoridated water, who were followed up for an average of 6.1 years $^{84}$, provide compelling evidence that lifelong exposure to fluoridated water does not increase the risk of hip fracture.

There is some evidence that some dietary constituents may inhibit calcium utilization by reducing calcium intestinal absorption or by increasing urinary calcium excretion. Oxalic acid, which is found in some vegetables (spinach, beans and sweet potatoes) is a potent inhibitor of calcium absorption. Phytic acid, which is found in seeds, is a modest inhibitor of calcium absorption. Sodium chloride is a major determinant of urinary calcium excretion. The renal tubular reabsorption of calcium is in part associated to the renal tubular reabsorption of sodium, so that an increase in urinary sodium excretion is accompanied by an increase in urinary calcium excretion. In young females it has been observed that for every additional gram of salt consumed, an extra $26 \mathrm{mg}$ of calcium are excreted in the urine ${ }^{85}$. Some clinical studies, but not all, suggest that habitual salt excess may contribute to bone $\operatorname{loss}^{86}$. In a prospective study of postmenopausal women a positive association between urinary sodium excretion and bone loss has been reported $^{87}$. However, no relationship between sodium excretion and BMD has been found in elderly men and women ${ }^{88}$. Although the evidence indicates that excessive salt consumption may contribute to bone loss, additional prospective studies on bone density are needed before specific recommendations can be made for sodium consumed as a salt and the risk of osteoporosis.

Phytoestrogens are plant compounds which have estrogen-like activity. Soy protein-containing food are a rich source of isoflavone phytoestrogens, such as genistein, daidzein and apigenin, which bind weakly to estrogen receptors. There is great interest in these substances, as lower rates of chronic diseases, including coronary heart disease and osteoporosis, have been associated with high dietary intake of soy-containing foods. Several recent epidemiological studies suggest that the prevalence of osteoporosis is lower among Asian women that among western women. This difference has been partially explained by phytoestrogens being consumed largely by Asians. Laboratory and animal studies indicate that these compounds may have beneficial effects on bone. In humans, a recent study has shown that soy isoflavones attenuate bone loss from the lumbar spine in estrogen-deficient perimenopausal women ${ }^{89}$. However, whether natural phytoestrogens are beneficial on osteoporosis in human beings is yet to be demonstrated.

\section{Calcium and vitamin $D$ recommended dietary allowances (RDAs)}

\section{Calcium RDAs and sources}

In recent years, there has been much uncertainty about the intake of calcium for various ages and physiological states. Based on the above evidence, a number of groups have developed recommendations for calcium intake throughout life. In the United States the first consensus was reached in 1989 by the National Institute of Health (NIH), that proposed the Recommended Dietary Allowances (RDAs) for calcium ${ }^{90}$. However, the RDAs in children, adolescent and postmenopausal women have been criticised as being too low ${ }^{91}$. This dispute seemed to be resolved with the 1994 Consensus Development Conference on Optimal Calcium Intake ${ }^{92}$. The consensus panel of NIH recommended increases in calcium intake for almost all age groups. Specifically, for adolescent, 1200-1500 mg/day; for adults up to age $65,1000 \mathrm{mg} / \mathrm{d}$; for postmenopausal women not receiving estrogen, $1500 \mathrm{mg} /$ day; and for everyone above age 65, $1500 \mathrm{mg} /$ day $^{92}$. Nevertheless, the calculations by which these figures were obtained have also been criticised $^{93}$. These values have been considered to be specific for the United States, where the intakes of both protein and sodium are much higher than those of Europe. More recently, the National Academy of Science (NAS) presented dietary reference intakes of calcium and other nutrients for the North American population ${ }^{94}$. These intakes result in the following RDAs estimates for various ages and states: ages 9 to 18 years, $1300 \mathrm{mg} /$ day; 19 to 50 years, $1000 \mathrm{mg} /$ day; above age 50, $1200 \mathrm{mg} /$ day; and pregnancy and lactation at older than 19 years, $1000 \mathrm{mg} /$ day $^{94}$.

In 1998, the expert committee of the European 
Community in the Report on Osteoporosis-Action on prevention $^{7}$, harmonizing the previous recommendations on calcium intake for the European Communities ${ }^{95}$, and the nutrition recommendations for the Nordic countries, has given the recommended daily dietary allowances for calcium at all stages of life (Table 6). These values, that are consistently lower than those of North America, are mainly based on the dietary calcium intake data collected in European countries. For the elderly population, above age 65 the RDA is $700-800 \mathrm{mg} / \mathrm{day}^{7}$.

The main sources of calcium in the diet are dairy products (milk, yoghurts and cheese) fish (sardines with bones), few vegetables and fruits. Of the principal food sources of calcium, dairy products have a higher bioavailability than vegetables ${ }^{96}$. Calcium rich mineral waters are also good sources. The optimal way to achieve adequate calcium intake is through the diet. However, when dietary sources are scarce or not well tolerated, calcium supplements may be used. Calcium carbonate, which also has low solubility, is the salt most widely used, but more soluble salts are also available ${ }^{97}$. The best time of the day to take calcium supplements, during meals or before sleep, is still a matter of discussion. Acute bioavailability of calcium supplements is greater with meals, but it varies with the product, with different foodstuffs, and with the individual characteristics of gastric emptying. The relatively insoluble calcium salts, such as calcium carbonate, should be taken with meals, since the acid aids their dissolution. However, with more soluble calcium salts the meal may contain constituents, such as phosphate, oxalate and phytate, which could interfere with calcium absorption. A recent study has shown that the fractional absorption of calcium supplements is as much greater as much slower is the gastric emptying $^{98}$. The observation that the circadian rhythm of bone resorption is characterized by an increase during the night, concomitant with an increase in PTH secretion, has led some investigators to suggest that the best time to take calcium supplements is before sleep. However, although

Table 6 Recommended dietary allowances for calcium (based on European and Nordic recommendations) ${ }^{7}$

\begin{tabular}{lcc}
\hline Group & Age (years) & Range $(\mathrm{mg})$ \\
\hline Newborn & $0-0.5$ & 400 \\
Children & $0.5-1.0$ & $360-400$ \\
& $1-3$ & $400-600$ \\
Men & $4-6$ & $450-600$ \\
& $7-10$ & $550-700$ \\
& $11-24$ & $900-1000$ \\
Women & $25-65$ & $700-800$ \\
& $65+$ & $700-800$ \\
& $11-24$ & $900-1000$ \\
Pregnant & $25-50$ & $700-800$ \\
Lactating & $50-65$ & 800 \\
\hline
\end{tabular}

some studies have shown a significant effect of calcium supplements on the circadian rhythm of bone resorption, the clinical utility of giving calcium before sleep has not been confirmed 99 .

Calcium is generally well tolerated and reports of significant side-effects are rare ${ }^{100}$. There has been concern that high calcium intakes may lead to urinary calculi. At this regard, a recent study in women found that dietary calcium intake was inversely related to the risk of stone formation, whereas the use of calcium supplements increased stone risk ${ }^{101}$. In some countries fortification of foods with calcium has been considered. Until now the addition of calcium to foods is not compulsory in any European country with the exception of the United Kingdom, where calcium is added to all flours ${ }^{7}$.

\section{Vitamin RDAs and sources}

Vitamin D insufficiency is a common problem in Europe, especially in elderly population. Skin synthesis under the influence of ultraviolet light is the main source of vitamin D. Natural dietary source of vitamin D are limited, and their contribution to vitamin D status becomes important only when sunlight exposure is restricted. The main dietary sources of vitamin D are fatty fish (salmon, sardines, tuna) and oils derived from them, some meat products (liver), eggs and wild mushrooms.

Data on dietary vitamin $\mathrm{D}$ intake are not available in may European countries. Nevertheless, it is generally considered that the vitamin D intake is low, particularly in high risk populations, such as elderly and institutionalised people. In the United States and Canada the low vitamin $\mathrm{D}$ intake has been considered to be due to a decreased intake of milk, the principal dietary source of the vitamin $\mathrm{D}$ in those nations. In the USA it has been shown that it takes an intake of about $600 \mathrm{IU} /$ day, from all sources, to sustain serum $25(\mathrm{OH}) \mathrm{D}$ levels and avoid a condition of vitamin D insufficiency in adults ${ }^{102}$. This is substantially above the current recommended daily allowance in the USA of only 200 IU for adults ${ }^{90}$.

Adequate sunlight exposure may prevent and cure vitamin $\mathrm{D}$ insufficiency. In the elderly a normal serum level of $25(\mathrm{OH}) \mathrm{D}$ can be achieved with regular sunlight exposure for 15-30 minutes daily ${ }^{103}$. Recently, a Dutch study conducted in female psychogeriatric patients with a mean age of 85 years, has shown that ultraviolet irradiation corrects vitamin D deficiency and suppresses secondary hyperparathyroidism ${ }^{93}$. In this study the ultraviolet irradiation, at half the minimal erythemal dose of the lower back, three times per week, resulted as effective as an oral vitamin D daily dose of $400 \mathrm{IU}^{104}$. However, the sunlight exposure or the ultraviolet irradiation are limited by concern about skin cancer and skin disease.

The most rational approach to reducing vitamin D insufficiency is supplementation. In Europe, the recommended dietary allowances for vitamin D have been 
Table 7 Recommended dietary allowances for vitamin D (based on European and Nordic recommendations) ${ }^{7}$

\begin{tabular}{lcc}
\hline Group & Age (years) & Range $(\mu \mathrm{g})^{*}$ \\
\hline Newborn & $0-0.5$ & $10-25$ \\
Children & $0.5-1.0$ & $10-25$ \\
& $1-3$ & 10 \\
& $4-6$ & $0-10$ \\
Men and Women & $7-10$ & $0-10$ \\
& $11-14$ & $0-15$ \\
Pregnant & $15-17$ & $0-15$ \\
Lactating & $18-64$ & $0-10$ \\
& $65+$ & 10 \\
\end{tabular}

* $1 \mu \mathrm{g}$ vitamin $\mathrm{D}=40 \mathrm{IU}$.

proposed in 1998 by the report on osteoporosis-action on prevention ${ }^{7}$. The requirement for dietary vitamin $\mathrm{D}$, based on European and Nordic recommendations, depends on the amount of sunshine exposure, according to a range where the higher limit is the estimated dietary requirement of an individual with minimal endogenous synthesis, whereas the lower limit indicates the intake of an individual able to produce adequate vitamin D (Table 7). The RDAs are $400 \mathrm{IU}(10 \mu \mathrm{g})$ daily for people aged 65 years or over. However, the available evidence suggest that in elderly and other high risk populations $800 \mathrm{IU}$ $(20 \mu \mathrm{g})$ daily should be advised ${ }^{105}$. This dose is safe and free of side effects. In fact, excess vitamin D intake should be avoided. Although the maximum safe dose is still unknown, intakes of $50 \mu \mathrm{g}$ (2000 IU) daily should not be exceeded to avoid some harmful effects, such as hypercalcemia and hypercalciuria. Fortification of foods with vitamin D provides an alternative approach. Supplementation of food with vitamin D is common in the USA, where milk is fortified with vitamin D, but is not common in Europe with the exception of some Northern countries (Belgium, Netherlands and United Kingdom) where fortification is compulsory only to margarines ${ }^{7}$.

In conclusion, in Europe suboptimal vitamin D status is very common in the elderly, mainly because of reduced sunlight exposure. Evidence supports routine supplementation for those people at risk of osteoporosis, by providing a daily intake of $400-800 \mathrm{IU}$. This is an effective, safe and cheap means of preventing osteoporotic fractures.

\section{References}

1 Consensus Development Conference. Diagnosis, prophylaxis and treatment of osteoporosis. Amer. J. Med. 1993; 94: 646-650.

2 World Health Organisation: Assessment of fracture risk and its application to screening for postmenopausal osteoporosis. Technical Report Series. WHO, Geneva, 1994.

3 Kanis JA, Melton LJ, Christiansen C, et al. The diagnosis of osteoporosis. J. Bone Min. Res. 1994; 9: 1137-1141.

4 Elffors L, Allander E, Kanis JA, et al. The variable incidence of hip fracture in Southern Europe; the MEDOS study. Osteoporosis Int. 1994; 4: 253-263.

5 Bacon WE, Maggi S, Looker A, et al. International comparison of hip fracture rates in 1988-89. Osteoporosis Int. 1996; 6: 69-75.

6 De Laet C., Van Hout BA, Pols H.A.P.: Osteoporosis in the Netherlands. IMTA Report 96.44, Rotterdam, 1996.

7 European Commission: Report on osteoporosis in the European Community - Action on prevention. Luxembourg Office for Official Publications of the European Communities, pp. 112, 1998.

8 O'Neill TW, Felsenberg D, Varlow J, et al. The prevalence of vertebral deformity in European men and women: the European Vertebral Osteoporosis Study. J. Bone Min. Res. 1996; 11: 1010-1018.

9 Cooper GS. Genetic studies of osteoporosis: what have we learned. J. Bone Min. Res. 1999; 14: 1646-1648.

10 Chapuy MC, Preziosi P, Maamer M, et al. Prevalence of vitamin D insufficiency in an adult normal population. Osteoporosis Int. 1997; 7: 439-443.

11 Ringe JD. Vitamin D deficiency and osteopathies. Osteoporosis Int. 1998; 8: S35-S39.

12 Sahota O, Masud T, San P, et al. Vitamin D insufficiency increases bone turnover markers and enhances bone loss at the hip in the patients with established vertebral osteoporosis. Clin. Endocrinol. 1999; 51: 217-221.

13 Valimaki MJ, Karkkainen M, Lamberg-Allardt C, et al. Exercise, smoking, and calcium intake during adolescence and early adulthood as determinants of peak bone mass. Cardiovascular Risk in Young Finns Study Group. BMJ 1994; 309: 230-235.

14 Jackman LA, Millane SS, Martin BR, et al. Calcium retention in relation to calcium intake and postmenarcheal age in adolescent females. Am. J. Clin. Nutr. 1997; 66: 327-333.

15 Welten DC, Kemper HC, Post GB, et al. A meta-analysis of the effect of calcium intake on bone mass in young and middle aged females and males. J. Nutr. 1995; 25: 28022813.

16 Cummings SR, Black DM, Nevitt MC, et al. Bone density at various sites for prediction of hip fractures. The Study of Osteoporotic Fractures research Group. Lancet 1993; 341: $72-75$.

17 Kanis JA. The use of calcium in the management of osteoporosis. Bone 1999; 24: 279-290.

18 Amorin Cruz JA, Moreiras O, Brzozowska A. Longitudinal changes in the intake of vitamins and minerals of elderly Europeans. Eur. J. Clin. Nutr. 1996; 50: S577-S585.

19 Kanders B, Dempster DW, Lindsay R. Interaction of calcium nutrition and physical activity on bone mass in young women. J. Bone Min. Res. 1988; 3: 145-149.

20 Johnston CC, Miller JZ, Slemenda CW, et al. Calcium supplementation and increases in bone mineral density in children. N. Engl. J. Med. 1992; 327: 82-87.

21 Dawson-Hughes B. Calcium insufficiency and fracture risk. Osteoporosis Int. 1996; 3: S37-S41.

22 Dawson-Hughes B. Calcium supplementation and bone loss: a review of controlled clinical trials. Am. J. Clin. Nutr. 1991; 54: S274-S280.

23 Nordin BE. Calcium and osteoporosis. Nutrition 1997; 3 664-686.

24 Dawson-Hughes B, Harris SS, Krall EA, et al. Effect of calcium and vitamin D supplementation on bone density in men and women 65 years of age or older. N. Engl. J. Med. 1997; 337: 670-676.

25 Dawson-Hughes B, Dallal GE, Krall EA, et al. A controlled trial of the effect of calcium supplementation on bone density in postmenopausal women. N. Engl. J. Med. 1990; 323: 878-883.

26 Elders PJ, Lips P, Netelenbos JC, et al. Long-term effect of 
calcium supplementation on bone loss in perimenopausal women. J. Bone Min. Res. 1994; 9: 963-970.

27 Nieves JW, Komar L, Cosman F, et al. Calcium potentiates the effect of estrogen and calcitonin on bone mass: review and analysis. Am. J. Clin. Nutr. 1998; 67: 18-24.

28 Eastell R, Yergey AL, Vieira NE, et al. Interrelationships among vitamin D metabolism, true calcium absorption, parathyroid function, and age in women: evidence of an age-related intestinal resistance to 1,25-dihydroxyvitamin D action. J. Bone Min. Res. 1991; 6: 125-132.

29 Kinyamu HK, Gallagher JC, Knezetic JA, et al. Effect of vitamin D receptor genotypes on calcium absorption, duodenal vitamin $\mathrm{D}$ receptor concentration, and serum 1,25 dihydroxyvitamin D levels in normal women. Calcif. Tissue Int. 1997; 60: 491-495.

30 Peacock M. Effect of calcium and vitamin D insufficiency on the skeleton. Osteoporosis Int. 1998; 8: S45-S51.

31 McKane WR, Khosla S, Egan KS, et al. Role of calcium intake in modulating age-related increases in parathyroid function and bone resorption. J. Clin. Endocrinol. Metab. 1996; 81: 1699-1703.

32 Compston J. The role of vitamin D and calcium supplementation in the prevention of osteoporosis fractures in the elderly. Clin. Endocrinol. 1995; 43: 393-405.

33 Haden ST, Brown EM, Hurwitz S, et al. The effects of age and gender on parathyroid hormone dynamics. Clin. Endocrinol. 2000; 52: 329-338.

34 Ruiz JC, Mandel C, Garabedian M. Influence of spontaneous calcium intake and physical exercise on the vertebral and femoral bone mineral density of children and adolescents. $J$. Bone Min. Res. 1995; 10: 675-682.

35 Mosekilde L. Osteoporosis and exercise. Bone 1995; 17: 193-195.

36 Prince R, Devine A, Dick I, et al. The effects of calcium supplementation (milk powder or tablets) and exercise on bone density in postmenopausal women. J Bone Min. Res. 1995; 10: 1068-1075.

37 Kanis JA, Johnell O, Gullberg B, et al. Evidence for the efficacy of drugs affecting bone metabolism in preventing hip fracture. BMJ 1992; 305: 1124-1128.

38 Recker RR, Hinders S, Davies KM, et al. Correcting calcium nutritional deficiency prevents spine fractures in elderly women. J. Bone Min. Res. 1996; 11: 1961-1966.

39 Chevalley T, Rizzoli R, Nydegger V, et al. Effects of calcium supplements on femoral bone mineral density and vertebral fracture rate in vitamin-D-replete elderly patients. Osteoporosis Int. 1994; 5: 245-252.

40 Reid IR, Ames RW, Evans MC, et al. Long-term effect of calcium supplementation on bone loss and fractures in postmenopausal women; a randomised controlled trial. Am.J. Med. 1995; 4: 331-335.

41 Webb AR, Pilbeam C, Hanafin N, et al. An evaluation of the relative contributions of exposure to sunlight and of diet to the circulating concentrations of 25hydroxyvitamin D in an elderly nursing home population in Boston. Am. J. Clin. Nutr. 1990; 51: 1075-1081.

42 McKenna MJ, Freaney R, Meade A, et al. Hypovitaminosis D and elevated serum alkaline phosphatase in elderly Irish people. Am. J. Clin. Nutr. 1985; 41: 101-109.

43 Gennari C, Agnusdei D, Nardi P, et al. Estrogen preserves a normal intestinal responsiveness to 1,25-dihydroxyvitamin D3 in oophorectomized women. J. Clin. Endocrinol. Metab. 1990; 71: 1288-1293.

44 Morris HA, Need AG, Horowitz M, et al. Calcium absorption in normal and osteoporotic postmenopausal women. Calcif. Tissue Int. 1991; 49: 240-243.

45 Lips P, Wiersinga A, Van Ginkel FC, et al. The effect of vitamin D supplementation on vitamin D status and parathyroid function in elderly subjects. J. Clin. Endocrinol. Metab. 1988; 67: 644-650.
46 Scharla SH. Prevalence of subclinical vitamin D deficiency in different European countries. Osteoporosis Int. 1998; 8: S7-S12.

47 McKenna MJ. Differences in vitamin D status between countries in young adults and the elderly. Am.J. Med. 1992; 93: 69-77.

48 Van Der Wielen RP, Lowik MR, Van Der Berg H, et al. Serum vitamin D concentrations among elderly people in Europe. Lancet 1995; 346: 207-210.

49 Chapuy MC, Schott AM, Garnero P, et al. Healthy elderly French women living at home have secondary hyperparathyroidism and high bone turnover in winter. J. Clin. Endocrinol. Metab. 1996; 81: 1129-1133.

50 Meunier PJ, Chapuy MC, Arlot ME, et al. Can we stop bone loss and prevent hip fractures in the elderly? Osteoporosis Int. 1994; 4: S71-S76.

51 Martinez ME, Delcampo MJ, Sanchez-Cabezudo MJ, et al. Relations between calcidiol serum levels and bone mineral density in postmenopausal women with low bone density. Calcif. Tissue Int. 1994; 55: 253-256.

52 Rosen CJ, Morrison A, Zhou H, et al. Elderly women in northern New England exhibit seasonal changes in bone mineral density and calciotropic hormones. Bone Min. 1994; 2: 83-92.

53 Ooms ME, Lips P, Roos JC, et al. Vitamin D status and sex hormone binding globulin: determinants of bone turnover and bone mineral density in elderly women. J. Bone Min. Res. 1995; 10: 1177-1184.

54 Scharla SH, Scheidt-Nave C, Leidig G, et al. Lower serum 25hydroxyvitamin $\mathrm{D}$ is associated with increased bone resorption markers and lower bone density at the proximal femur in normal females: a population-based study. Exp. Clin. Endocrinol. Diabetes 1996; 104: 289-292.

55 Villareal DT, Civitelli R, Chines A, et al. Subclinical vitamin D deficiency in postmenopausal women with low vertebral bone mass. J. Clin. Endocrinol. Metab. 1991; 72: 628-634.

56 Khaw KT, Sheyd MJ, Compston J. Bone density, parathyroid hormone and 25-hydroxyvitamin D concentrations in middle-aged women. BMJ 1992; 305: 273-277.

57 Dawson-Huges B, Dallal GE, Krall EA, et al. Effect of vitamin $\mathrm{D}$ supplementation on overall bone loss in healthy postmenopausal women. Ann. Inter. Med. 1991; 115: 505512.

58 Nordin BE, Baker MR, Horsman A, et al. A prospective trial of the effect of vitamin D supplementation on metacarpal bone loss in elderly women. Am. J. Clin. Nutr. 1985; 42 : 470-474.

59 Dawson-Huges B, Harris SS, Krall EA, et al. Rates of bone loss in postmenopausal women randomly assigned to one of two dosages of vitamin D. Am. J. Clin. Nutr. 1995; 61: $1140-1145$.

60 Ooms ME, Roos JC, Bezemer PD, et al. Prevention of bone loss by vitamin D supplementation in elderly women: a randomized double blind trial. J. Clin. Endocrinol. Metab. 1995; 80: 1052-1058.

61 Orwoll ES, Oviatt SK, McClung MR, et al. The rate of bone mineral loss in normal men and the effects of calcium and cholecalciferol supplementation. Ann. Intern. Med. 1990; 112: 29-34.

62 Chapuy MC, Arlot ME, Duboeuf F, et al. Vitamin D3 and calcium to prevent hip fractures in elderly women. N. Engl. J. Med. 1992; 237: 1637-1642.

63 Krieg MA, Jacquet AF, Bremgartner M, et al. Effect of supplementation with vitamin D3 and calcium on quantitative ultrasound of bone in elderly institutionalised women: a longitudinal study. Osteoporosis Int. 1999; 9 483-488.

64 Chapuy MC, Arlot ME, Delmas PD, et al. Effect of calcium and cholecalciferol treatment for three years on hip fractures in elderly women. BMJ 1994; 308: 1081-1082. 
65 Lips P, Graafmans WC, Ooms ME, et al. Vitamin D supplementation and fracture incidence in elderly persons - a randomized, placebo-controlled clinical trial. Ann. Intern. Med. 1996; 124: 400-406.

66 Heikinheimo RJ, Inkovaara JA, Harjv EJ, et al. Annual injections of vitamin D and fractures of aged bone. Calcif. Tissue Int. 1992; 51: 105-110.

67 Lips P. Vitamin D deficiency and osteoporosis: the role of vitamin $D$ deficiency and treatment with vitamin $D$ and analogues in the prevention of osteoporosis-related fractures. Eur. J. Clin. Invest. 1996; 26: 436-442.

68 Weaver CM, Peacock M, Johnston CC. Adolescent nutrition in the prevention of postmenopausal osteoporosis. J. Clin. Endocrinol. Metab. 1999; 84: 1839-1843.

69 Bonjour J-P, Schurch MA, Rizzoli R. Nutritional aspects of hip fractures. Bone 1996; 18: s139-S144.

70 Geinoz G, Rapin CH, Rizzoli R, et al. Relationship between bone mineral density and dietary intakes in the elderly. Osteoporosis Int. 1993; 3: 242-248.

71 Orwoll ES. The effects of dietary protein insufficiency and excess on skeletal health. Bone 1992; 13: 343-350.

72 Conlan D, Korula R, Tallentire D. Serum copper levels in elderly patients with femoral neck fractures. Age Ageing 1990; 19: 212-214.

73 Herzberg M, Foldes J, Steinberg R, et al. Zinc excretion in osteoporotic women. J. Bone Min. Res. 1990; 5: 251-257.

74 Hodges SJ, Akesson K, Vergnaud P, et al. Circulating levels of vitamin K1 and K2 decreased in elderly women with hip fracture. J. Bone Min. Res. 1998; 8: 1241-1245.

75 Plantalech L, Guillaumont M, Vergnaud P, et al. Impairment of gammacarboxylation of circulating osteocalcin (bone Gla-protein) in elderly women. J. Bone Min. Res. 1991; 8: 1211-1216.

76 Szulc P, Chapuy MC, Meunier PJ, et al. Serum undercarboxylated osteocalcin is a marker of the risk of hip fracture in elderly women. J. Clin. Invest. 1993; 91: 17691774.

77 Szulc P, Arlot M, Chapuy MC, et al. Serum undercarboxylated osteocalcin correlates with hip bone mineral density in elderly women. J. Bone Min. Res. 1994; 9: 15911595.

78 Lemann J, Favus MJ. The intestinal absorption of calcium, magnesium, and phosphate. Primer on the metabolic bone diseases and disorders of mineral metabolism. Fourth Edition. Philadelphia: Lippincot Williams and Wilkins, 1999: 63-67.

79 Karkainen M, Lamberg-Allardt C. An acute intake of phosphate increases parathyroid hormone secretion and inhibits bone formation in young women. J. Bone Min. Res. 1996; 11: 1905-1912.

80 Reginster JY, Strause L, Deroisy R, et al. Preliminary report of decreased serum magnesium in postmenopausal osteoporosis. Magnesium 1989; 8: 106-109.

81 Simonen O, Laitinen O. Does fluoridation of drinking-water prevent bone fragility and osteoporosis? Lancet 1985; 2: 432-434.

82 Kroger H, Alhava E, Honkanen R, et al. The effect of fluoridated drinking water on axial bone mineral density a population based study. Bone Min. 1994; 27: 33-41.

83 Hillier S, Cooper C, Kellingray S, et al. Fluoride in drinking water and risk of hip fracture in the UK: a case-control study. Lancet 2000; 355: 265-269.

84 Cauley JA, Murphy PA, Riley PJ, et al. Effects of fluoridated drinking water on bone mass and fractures: the study of osteoporotic fractures. J. Bone Min. Res. 1995; 10: 10761086.

85 Matkovic V, Ilich JZ, Andon MB, et al. Urinary calcium, sodium and bone mass of young females. Am. J. Clin. Nutr. 1995; 62: 417-425.

86 Masey LK, Whiting SJ. Dietary salt, urinary calcium, and bone loss. J. Bone Min. Res. 1996; 11: 731-736.

87 Devine A, Criddle RA, Dick IM, et al. A longitudinal study of the effect of sodium and calcium intakes on regional bone density in postmenopausal women. Am. J. Clin. Nutr. 1995; 62: $740-745$.

88 Dawson-Hughes B, Fowler SE, Dalsky G, et al. Sodium excretion influences calcium homeostasis in elderly men and women. J. Nutr. 1996; 126: 2107-2112.

89 Alekel DL, Peterson C, Germain ASt, et al. Isoflavone-rich soy isolate exerts significant bone-sparing in the lumbar spine of perimenopausal women. J. Bone Min. Res. 1999; 14(Suppl. 1): S208.

90 NIH. Recommended Dietary Allowances. 10th edn. Washington DC: National Academic Press, 1989.

91 Nordin BEC, Heaney RP. Calcium supplementation of the diet:justified by present evidence. BMJ 1990; 300: 10561060 .

92 NIH Consensus Conference. Optimal Calcium Intake. JAMA 1994; 272: 1942-1948.

93 Kanis JA. Calcium nutrition and its implications for osteoporosis. Eur. J. Clin. Nutr. 1994; 48: 833-841.

94 National Academy of Science: Institute of Medicine. Dietary reference intakes for calcium, phosphorus, magnesium, vitamin D and fluoride. Standing committee on the scientific evaluation of dietary reference intakes. Food and Nutrition Board. Washington DC: National Academy Press, 1997.

95 Commission of the European Communities: Reports of the scientific committee for food. 31st series, 1993.

96 Karkkainen MUM, Wiersam JW, Lambergallardt CJE. Postprandial parathyroid hormone response to four calciumrich foodstuffs. Am. J. Clin. Nutr. 1997; 65: 1726-1730.

97 Heaney RP, Dowell MS, Barger-Lux MJ. Absorption of calcium as the carbonate and citrate salts, with some observations on method. Osteoporosis Int. 1999; 9: 19-23.

98 Wishart JM, Horowitz M, Morris HA, et al. Relationship between fractional calcium absorption and gastric emptying. Eur. J. Clin. Invest. 1995; 25: 123-127.

99 Aerssens J, Declerck K, Maeyaert B, et al. The effect of modyfing dietary calcium intake pattern on the circadianrhythm of bone resorption. Calcif. Tissue Int. 1999; 65: 3440.

100 Whiting SJ, Wood RJ. Adverse effects of high-calcium diets in humans. Nutrition Reviews 1997; 55: 1-9.

101 Curhan GC, Willett WC, Speizer FE, et al. Comparison of dietary calcium with supplemental calcium and other nutrients as factors affecting the risk for kidney stones in women. Ann. Intern. Med. 1997; 126: 497-504.

102 Holick MF. Vitamin D-new horizons for the 21st century. Am. J. Clin. Nutr. 1994; 60: 619-630.

103 Reid IR, Gallagher DJA, Bosworth J. Prophylaxis against vitamin $\mathrm{D}$ deficiency in the elderly by regular sunlight exposure. Age Ageing 1986; 15: 35-40.

104 Chel VGM, Ooms ME, Popp-Snijders C, et al. Ultraviolet irradiation corrects vitamin D deficiency and suppressess secondary hyperparathyroidism in the elderly. J. Bone Min. Res. 1998; 13: 1238-1242.

105 Compston JE. Vitamin D deficiency: time for action. BMJ 1998; 317: 1466-1467. 